\title{
Direcciones en que se desarrollará la Psicología Ambiental en los años futuros
}

\author{
Henry Granada \\ Universidad del Valle, Cali, Colombia
}

I ntentar aportes a la respuesta del encabezamiento de este breve escrito implica por lo menos dos optimismos: a) que la vida humana tiene perspectivas de desarrollo (aún en contra de evidencias de meramente crecimiento, e.g., actual invasión de Irák), b) que la Psicología Ambiental tiene un espacio de conocimiento y acción en ese derrotero. Ambas posibilidades las asumo y por ello escribo lo siguiente.

Granada (2002) señaló cinco puntos claves en los cuales la Psicología Ambiental (PA) convergía a pesar de diferencias entre autores y tendencias: a) énfasis en la interacción entre el sujeto social y el ambiente sin privilegiar, por principio, el dominio de uno u otro; b) la interacción entre ambos genera, a su vez, un sistema cualitativamente diferente (supersistema: $\mathrm{S}$ x A) de las propiedades y comportamientos de cada uno por separado; c) la posibilidad y necesidad de usar en forma legítima modalidades investigativas diferentes; d) aceptación y énfasis sobre fenómenos de tipo subjetivo tales como intencionalidad, significación y representación, no tanto por oposición sino como complemento y superación al énfasis objetivador; d) la necesidad creciente del enfoque inter, multi $\mathrm{y}$ transdiciplinario como estrategia que permita conocer e intervenir integralmente sobre las pautas de interacción S x A.

Gifford (1995) formuló que uno de los retos esenciales para la PA era la consecución de "mejores lugares", pero no dentro del concepto de utopía (lugares deseados no logrables) sino dentro del significado de entopía (lugares deseados logrables con esfuerzo). En síntesis planteaba que la misión de la PA se podría resumir en el esfuerzo científico-humano por el logro de mejores lugares para vivir. Como la mayoría de los efectos sobre el ambiente son acumulativos y muchos no aparecen ante los habitantes por su naturaleza sutil, en varias oportunidades las personas se adaptan aún ante escenarios peligrosos. Parte del trabajo de la PA estaría en contribuir a la toma de conciencia sobre adaptaciones inadecuadas y a la propuesta de alternativas mejores. En la misma dirección, Stokols (1995) propuso algunas tendencias del desarrollo de la PA que Granada (2002) resumió así:

a) el desarrollo de conceptos y métodos nuevos para analizar las relaciones entre ambiente y conducta; b) el incremento del énfasis en la investigación intercultural; c) los modelos transaccionales entre ambiente y conducta; $\mathrm{d}$ ) relaciones entre ambiente y grupo; e) la expansión de la aplicación de la investigación sobre ambiente y conducta a la solución de problemas comunitarios, y f) ampliación internacional del horizonte de acción (p. 7).
Evans (1996) por su parte, se refería a los “tópicos prominentes de investigación” y señalaba entre ellos la conexión cada vez mayor entre elementos del ambiente global y la psicología. Así mismo, reforzaba la idea de que dentro del campo de la psicología ambiental es crítico el rol de la cultura en el propósito de entender las relaciones entre los seres humanos. En su línea de pensamiento, Evans afirmaba el interés por entender la relación entre conducta criminal y diseño de ambientes físicos. También mencionó que estresores como ruido, densidad, polución y los desastres tecnológicos serán cada vez más objeto de atención por parte de la PA.

La inmensa mayoría de los autores, tanto de las ciencias naturales como sociales, entre los cuales se destaca Anglada (1997), subrayan que los cambios en la calidad del ambiente (esencialmente negativos) son producidos directa o indirectamente por causas humanas. Esto ofrece el reto y la oportunidad a la PA de estudiar y proponer alternativas de interacción a las pautas actualmente dominantes.

\section{Posibles tendencias}

Con en el propósito de no repetir lo anterior, pero sin poder sustraerme al emparentamiento con ello, haré énfasis en algunas tendencias. Tales se ubicarán tanto en el contexto regional como nacional (país Colombia) y algunas en el contexto internacional, especialmente latinoamericano.

1. Dentro del enfoque de la Ecología del Desarrollo Humano (Bronfenbrenner, 1987), la configuración y mantenimiento de la calidad de los microsistemas es vital para la calidad de vida presente y futura de la sociedad. Las díadas y n-íadas primarias y afectivas, los cambios de roles entre sujetos y la variedad, oportunidad y continuidad de actividades que vinculan a sus actores se convertirán más que hoy en objeto de cuidado especial: son más cercanos en la escala del control social endógeno, se puede hacer seguimiento menos costoso y con el enfoque de caso, se pueden proponer intervenciones planificadas y concertadas más fácilmente que cuando la escala es mayor. Así mismo, la sensibilidad a los cambios y a su dirección es detectable no solo por el "experto" sino por los participantes del microsistema. Aunque puedan variar contenidos temáticos (según cultura, problemas de urgencia o valores presentes) el enfoque y el nivel de la investigación-intervención se fortalecerá en gran variedad de escenarios: familia, trabajo, salud, recreación, cultura... Esto no contradice sino que complementa otros niveles que se propondrán luego. 
2. El concepto de transición, no solo entre ambiente y conducta propuesto por Stokols (1995), sino el de transición ecológica, es decir, entre microsistemas que interactúan conformando los mesosistemas, se volverá crítico pues es una de las fuentes claves de la socialización y aún dentro de niveles de control relativamene endógenos. El diseño social de estos niveles de interacción, el cual vincula el espacio y el tiempo (arquitectura, planificación, ingeniería, comunicación) entre recorridos y descansos de la cotidianidad, será una labor profesional y no sólo intuitiva entre los psicólogos sociales. Obviamente, la interacción entre los diferentes escenarios enriquecerá tanto la disciplina como los instrumentos operativos y conceptuales de la profesión. El acercamiento entre investigación y profesión será cada vez mayor pues la racionalidad que diferencia ambas disminuirá paulatinamente. Lo cotidiano será objeto privilegiado de investigación y no solo de "experiencia” pues logros en el campo como los relacionados con espacio personal, distancias psicológica y social, molestia por contaminantes, lenguaje no verbal, representaciones sociales, entre otros, señalan lo fructífero del enfoque y contenido. Sin embargo, los aspectos de la investigación "básica" no desaparecerán y, menos aún, en el conocimiento y exploración de sistemas nuevos: situaciones de ingravidez, deprivación continuada en el espacio y quizá uno de los espacios nuevos más importantes para el que hay que prepararse toda la vida: un mundo justo y en paz!

3. En el nivel del exo y macrosistema aparecen otros componentes que por densos y "lejanos" del control endógeno no son menos decisivos: los valores e ideologías, las políticas (gubernamentales o privadas), la normatividad nacional o internacional (derechos civiles, trato humanitario a prisioneros de guerra, medio ambiente...). Estos, aún en el caso de ser violados, y quizá en ese caso especialmente, pueden afectar de manera determinante la calidad de la vida entre microsistemas y mesosistemas. Es sumamente evidente en este punto la insuficiencia y quizá complicidad de tendencias positivistas que propenden por una supuesta neutralidad en aras de un gran valor: la objetividad. Asuntos como calidad de vida, "mejores" lugares, "desarrollo humano" etc. están "contaminados” hasta los huesos de componentes subjetivos (personales, sociales, inter-culturales) pero, paradójicamente, en ello reside su valor y su relevancia en la intervención social.

4. Dentro de la lógica del razonamiento anterior el concepto de sostenibilidad aplicado a la economía, a la cultura, a la vida misma, y a la calidad del ambiente se convierte en un espacio convocador de investigación, controversia y propuestas inter y transdisciplinarias: científicos sociales, científicos naturales, humanistas, saberes comunes de grupos y comunidades tienen un lugar natural allí en donde se pueda hablar de sociedad democrática y no autoritaria (desde cualquier punto de vista, incluso el de los expertos) pues se habla de modelos de desarrollo y de decisiones sobre el porvenir de todos. Luego todos deben estar allí. En consecuencia, la ruptura necesaria con el academicismo y el privilegio del saber científico como único o connotado conductor de las decisiones importantes y válidas aparece como necesaria y no como opcional. Ante esto, la ganancia cualitativa del concepto de participación adquiere un ribete o perfil sorprendente: serán los académicos los invitados a participar en los debates y proyectos de las comunidades y no al revés como sucede ahora!

5. El concepto de lugar, que ha relacionado tradicionalmente la antropología con la arquitectura, la planificación y la PA, mantendrá un puesto de importancia. Más aún, en cuanto referente para otros conceptos importantes como distancia social, intimidad y privacidad por ejemplo, el avance de la comunicación electrónica y los campos virtuales (espacial y temporalmente hablando) convertirá las nociones tradicionales de espacio, territorio y lugar en un verdadero campo de nuevas significaciones. La investigación sobre el sentido de lugar y su experiencia correspondiente ganarán en interés y novedad.

6. Dentro de estas posibilidades de futuro no puede olvidarse la perspectiva y enseñanza de la historia. En la coyuntura mundial que hoy se expresa en la invasión al Irak por parte de la “coalición”, existen una estructura y un recorrido largos ya señalados por los analistas: desde principios del siglo XX con la toma de Panamá (el nombre aquél de aquella invasión al istmo colombiano), pasando por el sinnúmero de participaciones en el derrocamiento (o asesinato) de líderes y gobernantes "inconvenientes” para la "libertad” (libre ejercicio de sus intereses), pasando por el apoyo activo de autócratas y dictadores sí convenientes. El gobierno de los E.U. de norteamérica y su gobierno oculto, las transnacionales, están condenados (no solo destinados, como dijo Bolívar) a invadir, engañar y chantajear a la humanidad para mantener y no solo para aumentar el actual nivel de condiciones de vida (crecimiento? desarrollo?) de sus glotones gobernados. Mientras ese modelo de crecimiento o de bienestar no cambie, las invasiones y el predominio del actual reordenamiento mundial continuará cambiando de ferocidad en el gesto pero con la misma cara. Aún más, esa política aislará al gobierno y a su pueblo en la medida en que éste apoye a aquél, pues "E. U. no tiene amigos, tiene intereses”.

7. Finalmente y de manera especial en los países en donde minorías (o mayorías!) étnicas y “especiales” (desplazados, inmigrantes) no solo persisten sino que se fortalecen, se desarrollará una etnopsicología: ésta podría surgir desde investigadores de países “desarrollados”, cuya curiosidad y visión así lo permita, pero los llamados son los profesionales y científicos que habitamos o conocemos esta realidad pero que aún no la valoramos. Esta vertiente presente y actuante desde hace centenios convoca a una psicología gestada y fortalecida desde acá pero no agotable en ese nuevo o "renovado” objeto de atención pues sería otra forma de chovinismo.

\section{Referencias}

Anglada, M. L. (1997). El cambio global en el medio ambiente. Introducción a sus causas humanas. México: Alfa \& Omega. 
Bronfenbrenner, U. (1987). Ecología del desarrollo humano. Buenos Aires: Paidós. Evans, G. (1996). Current trends in Environmental Psychology. IAAP Newsletter, Fall. Gifford, R. (1997). Environmental Psychology: principles and practice. Toronto: Allyn \& Bacon.
Granada, H. (2002). Psicología Ambiental: introducción temática. Barranquilla: Universidad del Norte.

Stokols, D. (1995). Instrumental and spiritual views of people environment relations. American Psychologist, 45(5), 641-644.

Henry Granada, mestre em Projetos de Desenvolvimento Social, Convenio Universidad del Norte - Université Paris-XII, é professor titular na Universidad del Valle, Cali - Colombia. Endereço para correspondência: Apartado aéreo 25534, Cali - Colombia. Tel.: 57-2-3153858. Fax: 57-2-3302123. E-mail: granadahe@yahoo.com 